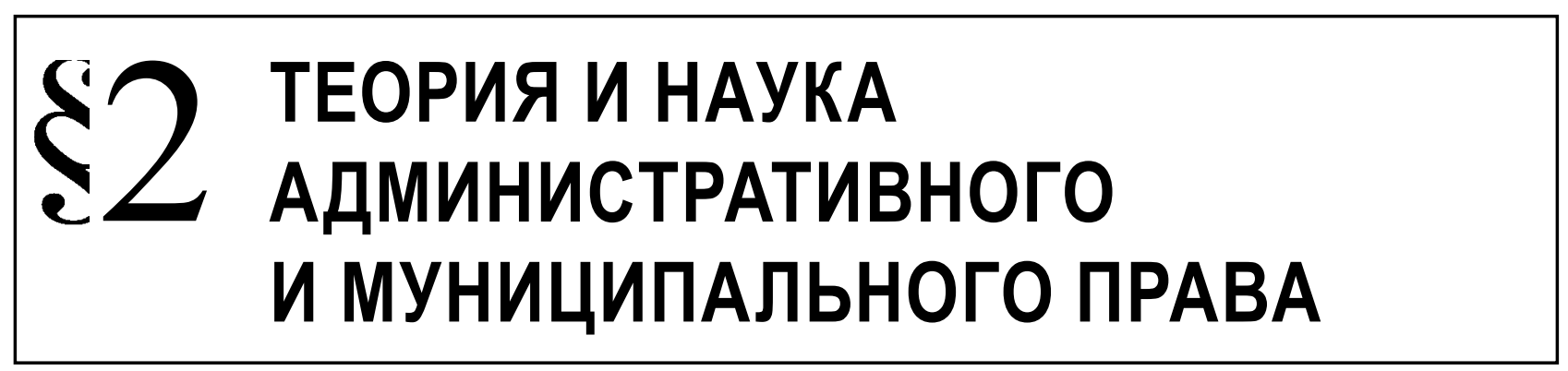

Романова Д.С.

\title{
«К ВОПРОСУ О КЛАССИФИКАЦИИ ТАМОЖЕННОГО КОНТРОЛЯ»
}

Аннотация. Предметом исследования является таможенный контроль как сложное явление, включающие в себя комплекс мероприятий таможенных органов, охватывающий весь процесс совершения таможенных операций и применения таможенных процедур, длящийся в течение продолжительного времени, имеющий сложный объект и предмет.Автором подробно рассматривается значимость и ценность классификации таможенного контроля, которая позволяет систематизировать знания о таможенном контроле, облегчить уяснение и понимание его сущности, улучшить теоретико-правовой аппарат, а также повысить эффрективность правоприменительной деятельности таможенных органов. Методология исследования основана на анализе действующего таможенного законодательства, а также научной литературы в области таможенного дела. Также, в исследовании использованы такие общенаучные методы, как: диалектический, анализ, синтез, дедукция, индукция. В процессе работы применялись также частнонаучные методы исследования: сравнительноправовой, системно-структурный, совместно с системным анализом. Особым вкладом автора в исследование темы является выделение критериев классификации таможенного контроля, позволяющих определить границы проведение таможенного контроля, его объект и предмет.В ходе исследования разработана авторская классификация таможенного контроля, основанная на логической последовательности совершения таможенных операций и таможенных процедур и времени осуществления таможенного контроля, а также классификация, критерием которой является основная цель таможенного контроля.Научная новизна заключается в отсутствии подобного рода исследования, либо незначительный характер имеющихся.

Ключевые слова: таможенный контроль, классификация, предварительное декларирование, цель таможенного контроля, таможенно-тарифное регулирование, запреты и ограничения, таможенная операция, таможенная процедура, публичный интерес, виды таможенного контроля.

Abstract. The research subject is customs control as a complex phenomenon including a set of long-term measures of customs agencies, covering customs operations and customs procedures, having a complex object and subject. The author considers the role and importance of customs control classification which allows one to systematize the knowledge about customs control, simplify interpretation and understanding of its essence, improve the theoretical basis, and raise the effectiveness of law enforcement activity of customs agencies. The research methodology is based on the analysis of the current customs legislation and scientific literature in the sphere of customs law. The author applies the dialectical method, analysis, synthesis, deduction and induction, the comparative-legal and system-structural methods and system analysis. The author defines customs control classification criteria allowing one to define the limits of customs control, its object and subject. The author develops her own classification of customs control based on the logical sequence of customs operations and procedures and customs control timing, and the classification based on the main purpose of customs control. The scientific novelty is conditioned by the absence of studies in this sphere or their insufficiency.

Key words: customs operations, prohibitions and restrictions, customs and tariff regulation, purpose of customs control, preliminary declaration, classification, customs control, customs procedure, public interest, forms of customs control.

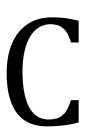

овершенствование таможенного контроля на сегодняшний день является одним из при-

оритетных направлений взаимодействия таможенных служб государств-членов Евразийского экономического союза (далее - ЕАЭС). Связана эта тенденция с тем, что таможенный контроль как основополагающая функция таможенных органов выполняет ряд задач, направленных, в первую очередь, на защиту экономических и национальных интересов государств-членов ЕАЭС. Таможенные органы, реализуя свою основную функцию, предотвращают ввоз на территорию ЕАЭС товаров, 
опасных для жизни и здоровья населения, а также товаров, ввоз которых нарушает экономические интересы государств-членов ЕАЭС.

В теории права нет однозначного понимания сущности таможенного контроля, несмотря на законодательное урегулирование данной правовой категории. Так, например, существует точка зрения, согласно которой под таможенным контролем при его широком толковании понимается вся процессуальная деятельность таможенных органов, в том числе совершение таможенных операций[1]. Также, под таможенным контролем понимают одно из средств реализации таможенной политики[2]. Д.Н. Бахрах рассматривает таможенный контроль как ключевой институт таможенного дела [3].

Различие точек зрения на данное явление порождает проблемы, связанные с правоприменением таможенными органами таможенного законодательства, а также с его соблюдением физическими и юридическими лицами, перемещающими товары через таможенную границу.

Для устранения неточности понятий используется логическая операция деления, разновидностью которой является классификация. Классификация имеет большое теоретическое и практическое значение и применяется по большей части для целей науки.

Под классификацией понимают общенаучный метод систематизации знания, направленный на организацию некоторой совокупности изучаемых объектов различных областей действительности, знания и деятельности, в систему соподчинённых групп (классов), по которым эти объекты распределены на основании их сходства в определённых сущностных свойствах [4].

Ценность логической операции классификации заключается в возможности определения места любого объекта в системе, установление наличия некоторых связей, а также раскрытие максимально полной информации об объекте в удобном для обозрения и распознавания виде.

Таможенный контроль является сложным явлением, включающим в себя комплекс мероприятий таможенных органов, охватывающий весь процесс совершения таможенных операций и применения таможенных процедур, длящийся в течение продолжительного времени (таможенный контроль после выпуска товаров проводится в течение трех лет), что существенно усложняет понимание его сущности.

Классификация таможенного контроля позволяет систематизировать знания о таможенном контроле, облегчить уяснение и понимание его сущности, улучшить теоретико-правовой аппарат, а также повысить эффективность правоприменительной деятельности таможенных органов.
Проведение классификации по нескольким критериям позволяет представить таможенный контроль в удобном для обозрения виде и максимально полно раскрыть его сущность.

Как указывают А.В. Малько, О.Ю. Бакаева, виды таможенного контроля - это составная часть таможенного контроля, обладающая всеми характерными чертами целого, однако отличающаяся от других частей целого в зависимости от выбранного критерия классификации [5].

На сегодняшний день одной из основных проблем для понимания сущности таможенного контроля является определение момента начала проведения таможенного контроля и момент его завершения.

Так, например, Халипов С.В. выделяет несколько этапов нахождения товаров и транспортных средств под таможенным контролем:

- таможенный контроль при осуществлении таможенных операций (основной или обязательный этап);

- таможенный контроль, связанный с применением таможенной процедуры (факультативный или возможный)[6].

Основываясь на Таможенном кодексе Таможенного союза (далее - ТК ТС), Федеральном законе «0 таможенном регулировании», научной литературе, практической деятельности таможенных органов, можно выделить такой критерий классификации таможенного контроля как логическая последовательность совершения таможенных операций и процедур и время осуществления таможенного контроля.

Под таможенными операциями понимают действия, совершаемые лицами и таможенными органами в целях обеспечения соблюдения таможенного законодательства. Одновременно с этим, таможенный контроль это совокупность мер, осуществляемых таможенными органами, в целях обеспечения соблюдения таможенного законодательства. На основании этого, можно сказать, что таможенные операции и таможенный контроль соотносятся как форма и содержание.

В философии форма и содержание характеризуют не само явление, а его сущность. Под формой понимают внешнее выражение содержания, устойчивую определенность элементов, их взаимодействие, характеризующееся пространственными и временными характеристиками[7]. Для таможенной операции, как для формы характерно наличие определённых субъектов, временных рамок, наличие организации элементов внутри системы.

Вместе с тем, содержание - это совокупность всех внутренних элементов и процессов, которые составляют данный предмет или явление[8]. Таможенный контроль, в частности, формы тамо- 


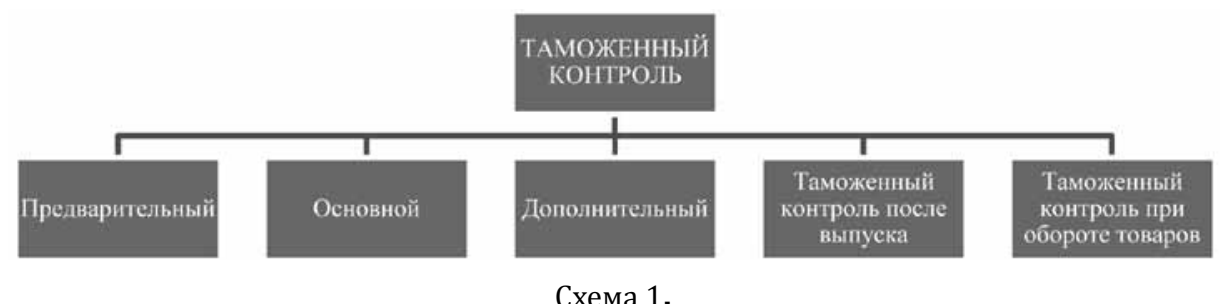

Схема 1.

женного контроля, установленные главой 16 ТК TC, являются содержанием таможенных операций, наполняя их основным смыслом, совершением определённых действий в целях соблюдения таможенного законодательства, которое обеспечивается посредством проведения таможенного контроля.

На основании логической последовательности совершения таможенных операций и таможенных процедур и времени осуществления таможенного контроля разработана авторская классификация видов таможенного контроля, согласно которой таможенный контроль делится на:

- предварительный таможенный контроль;

- основной таможенный контроль;

- дополнительный таможенный контроль;

- таможенный контроль после выпуска товаров;

- $\quad$ таможенный контроль при обороте товаров.

В связи с внедрением технологий предварительного информирования и предварительного декларирования, границы проведения таможенного контроля существенно расширяются.

Предварительный таможенный контроль осуществляется до момента прибытия товара на территорию ЕАЭС. Основным объектом предварительного таможенного контроля являются документы и сведения.

Предварительное информирование осуществляется путем представления документов и сведений через информационную систему таможенных органов до момента ввоза товаров и транспортных средств на территорию ЕАЭС.

Предварительное декларирование предполагает подачу таможенной декларации до момента ввоза иностранных товаров на таможенную территорию. Одновременно с подачей декларации таможенному органу в электронном виде представляются коммерческие и транспортные документы, имеющиеся в распоряжении декларанта.

Проверка документов и сведений является одной из форм таможенного контроля, что позволяет говорить о том, что таможенный контроль начинается до момента пересечения товарами и транспортными средствами границы ЕАЭС.

Особую актуальность при проведении таможенного контроля на этапе предварительного ин- формирования и предварительного декларирования приобретают способы таможенного контроля, в частности, формирование и использование информационных ресурсов [9].

Следующим видом таможенного контроля, является основной таможенный контроль, связанный с осуществлением таможенных операций.

Основной таможенный контроль преследует своей целью защиту публичных интересов государства. На данном этапе перед таможенными органами стоит ряд задач, направленных на обеспечение национальной и экономической безопасности государства, общественного порядка, жизни и здоровья людей, нравственности, моральных устоев и культурных ценностей общества.

Согласно статье 96 ТК ТС ввозимые товары находятся под таможенным контролем с момента пересечения таможенной границы, вывозимые товары с момента регистрации декларации на товары, либо совершения действий, непосредственно направленных на вывоз товаров и до пересечения таможенной границы.

Таможенный контроль при осуществлении таможенных операций может быть поделен на: таможенный контроль при осуществлении операций, предшествующих подаче декларации на товары, таможенный контроль, связанный с помещением товаров под таможенную процедуру.

Следующим видом таможенного контроля является дополнительный таможенный контроль, связанный с применением таможенных процедур.

Если основной таможенный контроль призван защищать публичные интересы, то помещение товаров под таможенную процедуру является интересом частным, что влечет за собой особый порядок проведения таможенного контроля.

Как правило, таможенный контроль завершается после выпуска товаров, а также в случаях, установленных ст. 96 ТК ТС. При этом помещение товаров под таможенные процедуры: временный ввоз, временный вывоз, переработка на таможенной территории, переработка для внутреннего потребления, переработка вне таможенной территории, предполагает проведение таможенного контроля таможенным органом до момента исполнения обязательства лиц поместить дан- 
ные товары под завершающую таможенную процедуру.

На основании изложенного, можно выделить таможенные процедуры одномоментные, помещение под которые не требует проведение последующего таможенного контроля, так как товары выпускаются в свободное обращение без каких-либо ограничений, и процедуры, носящие несамостоятельный характер, которые в будущем требуют завершающей таможенной процедуры.

Как правило, процедуры, носящие несамостоятельный характер, связаны с предоставлением льгот по уплате таможенных платежей, при этом несоблюдение условий процедуры влечёт за собой выставление требований об уплате таможенных платежей. При применении декларантом процедуры, носящей несамостоятельный характер, товары продолжают находиться под таможенным контролем, что требует со стороны таможенных органов применение дополнительных форм таможенного контроля.

Таможенный контроль за соблюдением условий таможенной процедуры осуществляется таможенным органом того государства-члена ЕАЭС, на территории которого товары были выпущены в соответствии с такой таможенной процедурой, что позволяет осуществлять его более эффективно.

На сегодняшний день особую актуальность приобретает таможенный контроль после выпуска товаров, который согласно авторской классификации, является следующим видом таможенного контроля.

Таможенный контроль после выпуска товаров выполняет ряд задач, направленных на минимизацию таможенных формальностей, создание условий для развития внешнеэкономической деятельности, и, конечно, более эффективную реализацию обеспечения экономической и национальной безопасности Российской Федерации.

Внедрение таможенного контроля после выпуска товаров предусмотрено Международной конвенцией об упрощении и гармонизации таможенных процедур от 18 мая 1973 года в редакции Протокола от 26 июня 1999 г., Генеральным соглашением по тарифам и торговле от 1994 года, в целях ускорения и упрощения совершения таможенных операций.

Следования международным стандартам в области таможенного дела позволяет ускорять совершение таможенных операций, перенося таможенный контроля на момент после выпуска товаров, и совершенствовать право Евразийского экономического союза, применяя современные методы и рекомендации, предусмотренные международными актами.

Таможенный контроль после выпуска товаров способствует развитию доверительных отношений между таможенным органом и декларантом, в связи с тем, что таможенный орган, полагаясь на репутацию и добропорядочное поведение декларанта, не применяет дополнительные формы таможенного контроля в целях ускорения совершения таможенных операций.

Последующий контроль может повысить эффективность всей системы таможенного контроля при использовании ряда таможенных процедур, в том числе для таких процедур, применение контроля на границе для которых просто малоэффективно.

По результатам таможенного контроля после выпуска товаров в 2015 году в рамках своей компетенции таможенные органы доначислили таможенных платежей и штрафов на сумму 767 млн. рублей, взыскали таможенных платежей и штрафов на сумму 133 млн. рублей.

Не менее важным видом таможенного контроля является таможенный контроль при обороте товаров.

Таможенный контроль при обороте товаров проводится таможенными органами в целях проверки сведений, подтверждающих факт выпуска таких товаров в соответствии с требованиями и условиями таможенного законодательства, в том числе в целях проверки наличия на товарах маркировки и иных идентификационных знаков.

Основной причиной существования таможенного контроля при обороте товаров является необходимость противодействия незаконному перемещению товаров.

Таким образом, на основании критерия логической последовательности совершения таможенных операций и процедур, а также времени осуществления таможенного контроля разработана авторская классификация видов таможенного контроля.

В соответствии со статьей 2 Федерального закона «0 таможенном регулировании» под таможенным делом понимается совокупность средств и методов обеспечения соблюдения мер таможенно-тарифного регулирования, а также запретов и ограничений при ввозе и вывозе товаров.

Таможенно-тарифное и нетарифное регулирование является инструментами реализации таможенного дела, основным институтом которого является таможенный контроль. Обеспечение соблюдения мер таможенного-тарифного регулирования и запретов и ограничений является целью таможенного контроля.

В связи с чем, в соответствии с основной целью таможенного контроля, можно выделить:

- таможенный контроль за соблюдением мер таможенно-тарифного-регулирования; 


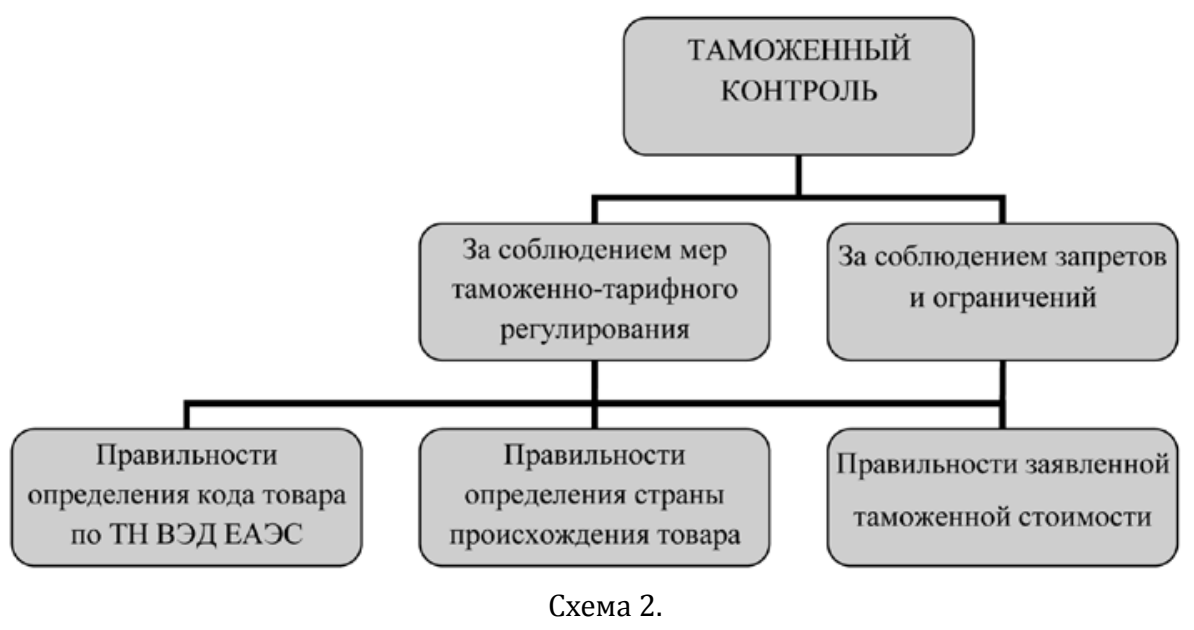

- таможенный контроль за соблюдением запретов и ограничений при перемещении товаров. В рамках данной классификации может быть проведена более подробная группировка видов таможенного контроля.

В статье 183 ТК ТС представлен перечень документов, которые представляются таможенному органу при таможенном декларировании. Данный перечень содержит документы, представление которых должно подтверждать соблюдение мер таможенно-тарифного регулирования и запретов и ограничений.

При этом информация, содержащаяся в данных документах, будет являться предметом таможенного контроля на стадии выпуска товаров, в связи с тем, что предметом таможенного контроля выступает то, на что непосредственно направлена проверочная деятельность таможенных органов, то есть применительно ко всем формам таможенного контроля, предметом выступают сведения.

В связи с чем, таможенный контроль за соблюдением мер таможенно-тарифного регулирования и запретов и ограничений может содержать в себе следующие виды таможенного контроля:
- таможенный контроль правильности определения классификационного кода товара по ТН ВЭД ЕАЭС;

- таможенный контроль правильности определения страны происхождения товара;

- таможенный контроль правильности заявленной таможенной стоимости и др.

Таким образом, в рамках данного исследования были выделены некоторые критерии классификации таможенного контроля, в теории права разработаны и иные классификации, которые не были предметом рассмотрения данной статьи.

Значимость и ценность классификации определяется возможностью систематизации и упорядочивания знания о каком-либо явлении. Разработка классификации таможенного контроля позволяет устранить противоречия в понимании границ проведения таможенного контроля, предмета и объекта таможенного контроля, а также проблемы, возникающие в рамках правоприменительной деятельности таможенных органов. Знания о таможенном контроле как сложном комплексе различных мероприятий таможенных органов могут быть систематизированы посредством классификации, осуществляемой по различным основаниям.

\section{Библиография:}

1. Новиков А. Б. Таможенный контроль в системе административных процедур таможенного дела//Законодательство и экономика.-2005.-№ 12.-С.12.

2. Тимошенко И. В. Таможенное право России. Ростов н/Д. : Феникс.-2001.-С. 347.

3. Бахрах Д. Н. Таможенное право как институт административного права // Государство и право.-М.-1995.-№ 3.C. 16.

4. А. Л. Субботин. В. Л. Абушенко. В. А. Бочаров. А. Эдельман. Классификация. Гуманитарная энциклопедия [Электронный ресурс] // Центр гуманитарных технологий. .-URL: http://gtmarket.ru/concepts/6879.-Дата обращения: 22.05.2016.

5. Малько А.В., Бакаева О.Ю. Таможенный юридический словарь-справочник.-М: Проспект.-С.213.

6. Халипов С.В. Таможенное право.-М: Юриспруденция.-2012.-С.166.

7. Алексеев П.В., Панин А.В. Философия.-М: ТК Велби.-2005.-С. 136.

8. Щерба С.П. Философия.-К:Кондор.-2011.-С.172. 
9. Мозер С.В. Цэрэнчимэдийн Цагаанцоож Экономические и правовые аспекты таможенного контроля товаров в системе таможенного администрирования // Научно-практическая конференция «Актуальные проблемы публично-правового регулирования в сфере экономики и финансов»-23.06.2014.

\section{References (transliterated):}

1. Novikov A. B. Tamozhennyi kontrol' v sisteme administrativnykh protsedur tamozhennogo dela//Zakonodatel'stvo i ekonomika.-2005.-№ 12.-S.12.

2. Timoshenko I. V. Tamozhennoe pravo Rossii. Rostov n/D. : Feniks.-2001.-S. 347.

3. Bakhrakh D. N. Tamozhennoe pravo kak institut administrativnogo prava // Gosudarstvo i pravo.-M.-1995.-№ 3.-S. 16.

4. A. L. Subbotin. V. L. Abushenko. V. A. Bocharov. A. Edel'man. Klassifikatsiya. Gumanitarnaya entsiklopediya [Elektronnyi resurs] // Tsentr gumanitarnykh tekhnologii. .-URL: http://gtmarket.ru/concepts/6879.-Data obrashcheniya: 22.05.2016.

5. Mal'ko A.V., Bakaeva O.Yu. Tamozhennyi yuridicheskii slovar'-spravochnik.-M: Prospekt.-S.213.

6. Khalipov S.V. Tamozhennoe pravo.-M: Yurisprudentsiya.-2012.-S.166.

7. Alekseev P.V., Panin A.V. Filosofiya.-M: TK Velbi.-2005.-S. 136.

8. Shcherba S.P. Filosofiya.-K:Kondor-2011.-S.172.

9. Mozer S.V. Tserenchimediin Tsagaantsoozh Ekonomicheskie i pravovye aspekty tamozhennogo kontrolya tovarov v sisteme tamozhennogo administrirovaniya // Nauchno-prakticheskaya konferentsiya «Aktual'nye problemy publichnopravovogo regulirovaniya v sfere ekonomiki i finansov».-23.06.2014. 